\title{
The electrical structure across the Median Tectonic Line in east Shikoku, southwest Japan
}

\author{
Tadanori Goto $^{1 *}$, Satoru Yamaguchi ${ }^{2}$, Norihiko Sumitomo ${ }^{1}$, and Katsumi Yaskawa ${ }^{3}$ \\ ${ }^{1}$ Research Center for Earthquake Prediction, Disaster Prevention Research Institute, Kyoto University, Uji, Kyoto 611-0011, Japan \\ ${ }^{2}$ Department of Earth and Planetary Sciences, Faculty of Science, Kobe University, Nada, Kobe 657-8501, Japan \\ ${ }^{3}$ Southern Osaka University, Hirao, Mihara, Osaka 587-0022, Japan
}

(Received January 20, 1997; Revised March 23, 1998; Accepted April 9, 1998)

\begin{abstract}
The Median Tectonic Line (MTL) is one of the longest tectonic lines in Japan with the lateral movement. In order to investigate the subsurface structure around the MTL, we carried out the magnetotelluric soundings and the geomagnetic depth soundings in the northeastern Shikoku district, southwest Japan. We estimated the resistivity model at the depth from the surface to $10 \mathrm{~km}$, which explains the observed apparent resistivities and phases. The most remarkable feature of the resistivity model is that the subsurface extension of the MTL has a north dip down to $5 \mathrm{~km}$ depth. This dipping interface also corresponds to a reflection seismic result. The north dipping MTL cannot be created by just a present strike slip motion. It requires that the horizontally compressive stress dominated in the early stage of the fault.
\end{abstract}

\section{Introduction}

The Median Tectonic Line (MTL) is one of the longest tectonic lines in Japan with a length of about $1000 \mathrm{~km}$ (Fig. 1(a)). Geographycally, it is also clearly recognizable as a lineament. A simplified geological map of the Shikoku district is shown in Fig. 1(b). Two different Cretaceous metamorphic belts are in contact along the MTL; the Ryoke high-T and low-P metamorphic rocks and the Sambagawa high-P and low-T metamorphic rocks (Kimura et al., 1991). These two contrasting metamorphic belts cannot be created in situ. The MTL is believed to have played an important role to contact these different metamorphic belts, but the process has not been clarified. Our objective is to reveal subsurface structure of the MTL and put a geophysical constraint on the geological evolution of southwest Japan.

\section{Previous Studies}

Here, we review the previous geophysical works around the MTL. The subsurface structure of the MTL has been assumed as being subvertical because of the sharpness of the lineament and the large lateral displacements compared with the vertical ones (e.g., Okada, 1980). Contrarily, recent geophysical studies across the MTL (Ohno et al., 1989; Iseki et al., 1990; Kashihara, 1992; Yusa et al., 1992; Yoshikawa et al., 1992; and Ito et al., 1996) suggested a possible north dip of the MTL at a shallow depth $(<2 \mathrm{~km})$. In these studies, Yusa et al. (1992) and Ito et al. (1996) revealed the subsurface MTL down to the depth of about $5 \mathrm{~km}$ as a north-dipping reflector. However, the very cause of the observed reflector

\footnotetext{
*Now at: Department of Environmental Earth Sciences, Aichi University of Education, Kariya 448-8542, Japan.

Copy right (C) The Society of Geomagnetism and Earth, Planetary and Space Sciences (SGEPSS); The Seismological Society of Japan; The Volcanological Society of Japan; The Geodetic Society of Japan; The Japanese Society for Planetary Sciences.
}

is unknown in general (e.g. Jones, 1987). Moreover, the reflection survey is difficult to image a nearly vertical boundary such as a strike-slip fault and the north-dipping reflector may not coincide with the subsurface MTL. Other geophysical information is essential to interpret the subsurface geometry of the deep part of the MTL. In this study, we have selected a studied area close to the survey line of a previous seismic reflection study (Ito et al., 1996). Our magnetotelluric (MT) results can confirm the subsurface geometry of the MTL to a depth of several kilometers and put another independent constraint on the MTL structure. Near the surveyed area, Shiozaki (1994) studied the regional resistivity structure including the MTL. However his spatial sampling was too sparse to discuss the MTL itself.

\section{Observations}

We selected northeast Shikoku as the surveyed area where Ito et al. (1996) carried out their seismic reflection and gravity surveys. Figure 2 shows their survey line, our observed sites and the geological map. In this area, the MTL has the strike of about $\mathrm{N} 80^{\circ} \mathrm{E}$. On the northern side of the MTL, the Izumi group is distributed in a long and narrow sedimentary basin. The Izumi group mainly consists of thick turbiditic alternations of sandstone and shale in the Cretaceous (Kimura et al., 1991). To the north of the Izumi group, there is the Ryoke belt, which mainly consists of granites. The Sambagawa metamorphic belt is situated along the southern side of the MTL with a width of about $20 \mathrm{~km}$.

MT soundings were carried out in 1992 across the MTL and the surrounding area (Fig. 2). The following four frequency bands were used for MT soundings in order to cover a wide frequency range: $17.4 \mathrm{kHz}$ for the Very Low Frequency MT (VLF-MT), $8700 \mathrm{~Hz}$ to $4.2 \mathrm{~Hz}$ for the Audio frequency MT (AMT), 26.6 Hz to $7.8 \mathrm{~Hz}$ for the Extremely Low Frequency MT (ELF-MT) and $0.2 \mathrm{~Hz}$ to $0.01 \mathrm{~Hz}$ for the Ultra 


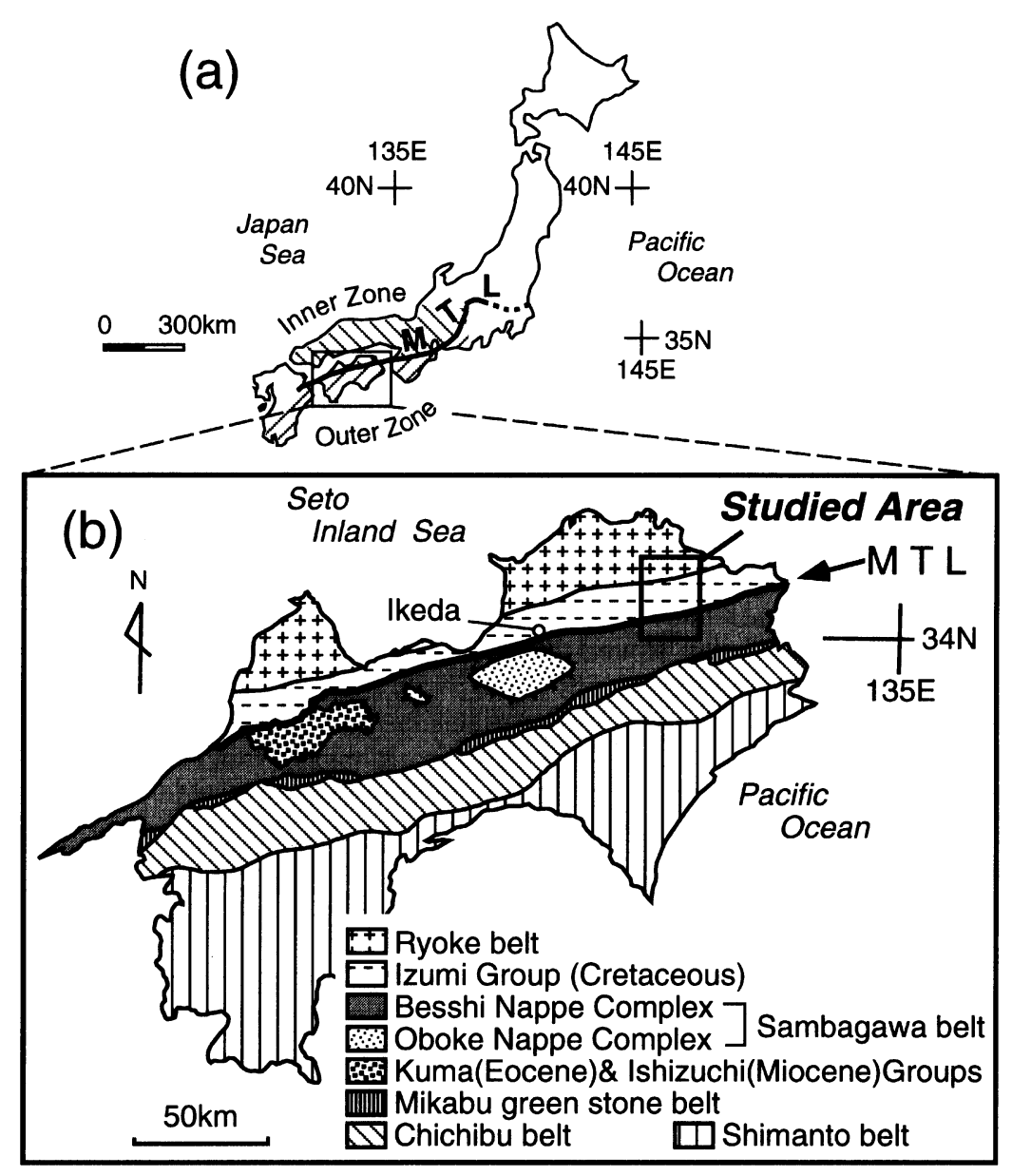

Fig. 1. Simplified geological map in southwest Japan (a) and Shikoku district (b). MTL means the Median Tectonic Line.

Low Frequency MT (ULF-MT). The location of MT sites is shown in Fig. 2. Impedance tensors were estimated from observed horizontal magnetic and electric fields by using the method after Vozoff (1972) and MT responses such as apparent resistivity and impedance phase were calculated. We also observed a vertical magnetic field at a number of sites to carry out geomagnetic depth soundings (GDS).

The VLF-MT measurements were carried out at 33 sites (Fig. 2) to determine the resistivity distribution near the surface. The source of the VLF signal was artificially emitted from about $300 \mathrm{~km}$ east of the studied area with the frequency of $17.4 \mathrm{kHz}$. The magnetic field at each site was polarized in about the N-S direction and the scalar impedance was obtained.

The AMT soundings were carried out at sites 20,23, 27 and 31 (Fig. 2). The natural fluctuations of the horizontal magnetic and electric fields were measured at 12 logarithmically equispaced frequencies between $8700 \mathrm{~Hz}$ and $4.2 \mathrm{~Hz}$. We directly calculated the Fourier coefficients of the electric and magnetic fields with the synchronous detectors at each frequency. After that, we selected good data sections based on a criterion of having 0.6 of high multiple coherency (Bendat and Piersol, 1971) between magnetic and electric fields. We then calculated impedance tensors, apparent resistivities and phases. Unfortunately, we were not able to obtain any good sections with high multiple coherency at site 20 because of severe artificial noise.

The ELF-MT soundings were carried out at 20 sites as shown in Fig. 2. We analyzed four modes of the Schumann resonance phenomena: 7.8, 13.9, 20.4 and $26.6 \mathrm{~Hz}$. The MT impedance tensors were calculated only from manually selected time series data to remove the noisy sections.

The ULF-MT soundings, with frequencies ranging from $0.2 \mathrm{~Hz}$ to $0.01 \mathrm{~Hz}$, were carried out at sites 20, 23, 27, 31 and 41 (Fig. 2). We recorded successive time series data of two electric and three magnetic components for about 5 days at each site with a $1 \mathrm{~Hz}$ sampling rate. In order to obtain MT parameters precisely, time series data were divided into subsections with 1024 data points. Then, multiple coherency between magnetic and electric fields and ordinary coherency between two horizontal magnetic fields (Bendat and Piersol, 1971) were calculated from every subsection. Good subsections were selected based on criteria of the high multiple coherency exceeding 0.6 and the low ordinary coherency below 0.4. Finally, MT impedance tensors were calculated from the good subsections selected above. We tried GDS at ULF-MT sites and estimated the induction arrows (Schmucker, 1970) from the same good data sections of the ULF-MT soundings. 


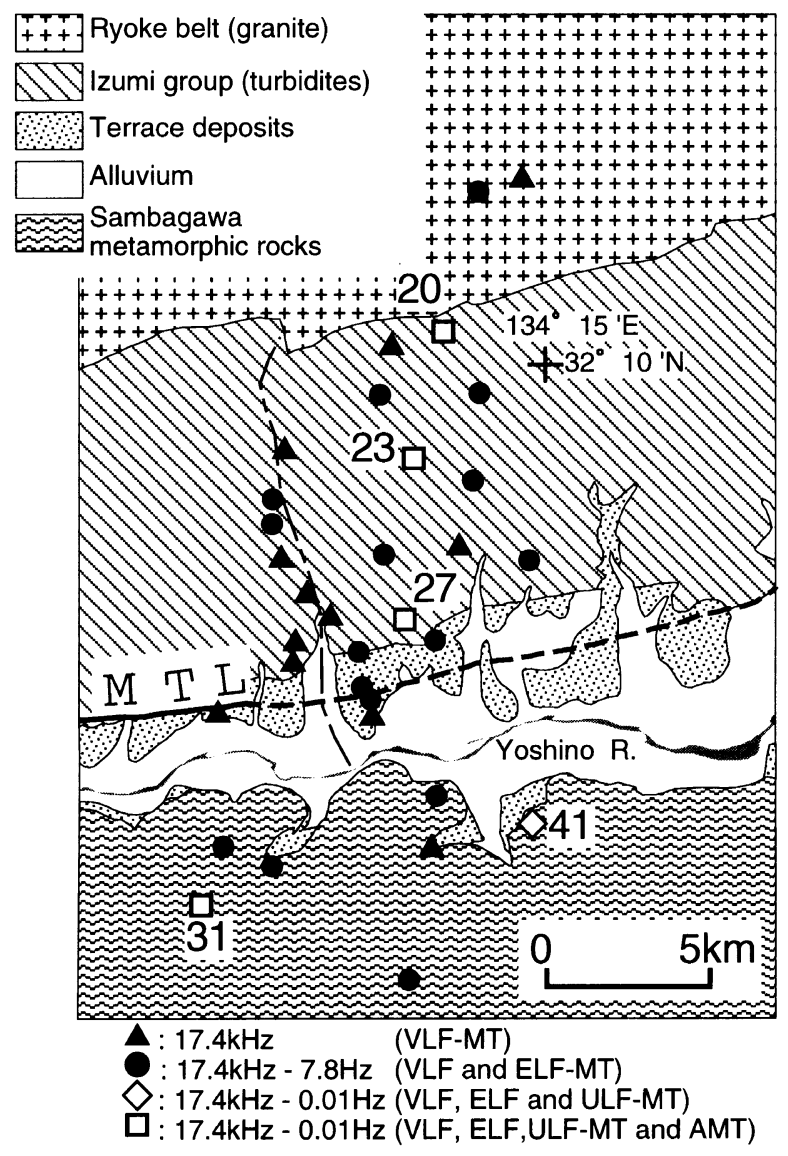

Fig. 2. Locations of magnetotelluric stations and geological map. Site numbers are appended to rectangular marks indicating the ULF-MT sites. The solid and dashed line indicate the location of the MTL. The survey line of the seismic reflection survey (Ito et al., 1996) is also indicated (dashed-dot line).

Most of the impedance tensors finally obtained by the AMT, ELF-MT and ULF-MT soundings showed the high multiple coherency beyond 0.6 between electric and magnetic fields and the low ordinary coherency below 0.4 between two horizontal magnetic fields. However, $32 \%$ of all impedances did not pass our criteria as the multiple coherency was higher than 0.6 and the magnetic coherency lower than 0.4 . A impedance showing low multiple coherence is possibly disturbed by strong artificial noises. A impedance tensor with high magnetic coherency is also erroneous because a denominator of impedance tensor becomes zero (Eq. (16) in Vozoff, 1972). We, therefore, did not include such unwanted impedance values in following discussions. Most of the impedances passing the above criteria show low skewness values (Swift, 1967) below 0.4. However, 21\% of the impedances showed skewness larger than 0.4 or indicated unrealistic phase values in two-dimensional cases (under $0^{\circ}$ or over $90^{\circ}$ ). We suppose that such MT impedances with large skewness or unrealistic phase were affected locally by threedimensional resistivity structures. As discussed later, we accept the resistivity structure as being approximately twodimensional in this study. So, we neglect MT impedances with a skewness larger than 0.4 or an unrealistic phase. As a result, about $54 \%$ of the observed impedances were available to elucidate the resistivity structure around the MTL.

\section{Results of MT Soundings and GDS}

In order to examine the regional strike of the resistivity structure around the studied area, the Groom-Bailey decomposition technique was applied (Groom and Bailey, 1989). The histograms of the inferred strike directions for two frequency bands $(7.8 \mathrm{~Hz}$ and $0.1-0.02 \mathrm{~Hz})$ are shown in Fig. 3. Although the strike direction has an ambiguity of $90^{\circ}$, only the strikes close to E-W direction were shown. It is recog-

(a) $7.8 \mathrm{~Hz}$

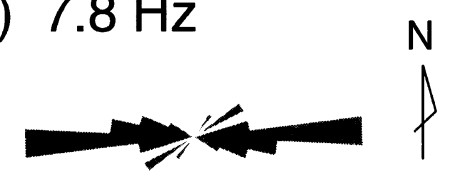

(b) $0.1-0.02 \mathrm{~Hz}$

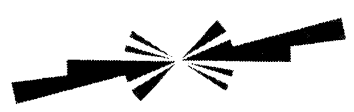

Fig. 3. Histograms of the directions of the impedance strikes (a) at $7.8 \mathrm{~Hz}$ and (b) in the frequency band between $0.1 \mathrm{~Hz}$ and $0.02 \mathrm{~Hz}$. 
nized in Fig. 3(a) that most of impedance strikes at $7.8 \mathrm{~Hz}$ show E-W direction. Figure 3(b) also shows that ENE-WSW direction is dominant in the impedance strikes at $0.1-0.02$ $\mathrm{Hz}$, although the unevenness of directions at $0.1-0.02 \mathrm{~Hz}$ is larger than those at $7.8 \mathrm{~Hz}$. The impedance strikes at high and low frequencies implies that the resistivity structure is approximately two-dimensional. Additionally, the induction

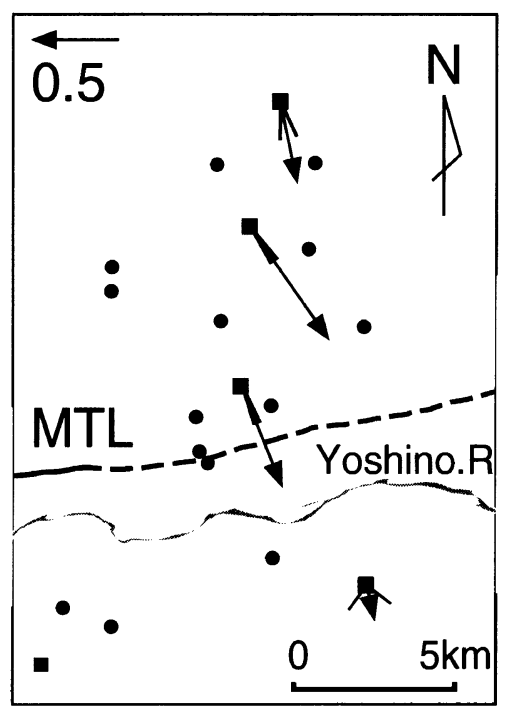

Fig. 4. Induction arrows (real part) averaged in the frequency range from $0.1 \mathrm{~Hz}$ to $0.03 \mathrm{~Hz}$. Ninety-five percent standard errors of direction are indicated at the foot of each induction arrow with thin line.

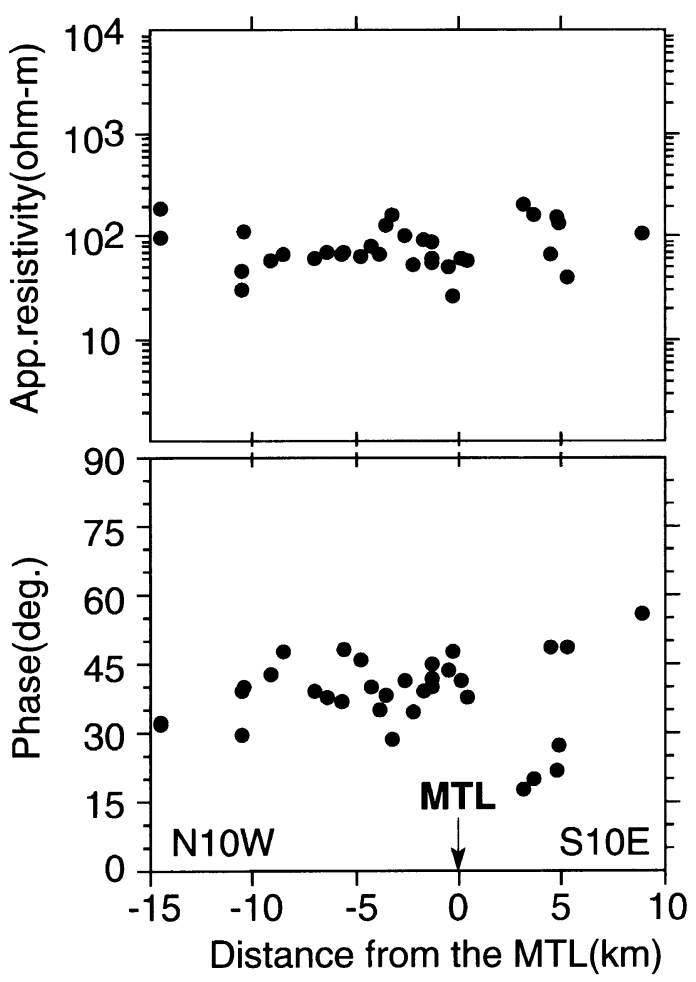

Fig. 5. Apparent resistivity and phase at $17.4 \mathrm{kHz}$ along the profile. arrows have almost SSE directions. The induction arrows in Fig. 4 are averaged ones in the frequency range from $0.1 \mathrm{~Hz}$ to $0.03 \mathrm{~Hz}$. The induction arrows are roughly perpendicular to the impedance strikes and the regional geological strike $\left(\mathrm{N} 80^{\circ} \mathrm{E}\right)$. Thus, the directions of impedance strikes and the induction arrows led us to conclude that the regional strike of the resistivity structure is about $\mathrm{N} 80^{\circ} \mathrm{E}$. Note that the induction arrows show the largest value on the northern side of the MTL and the smallest on the southern side.

The scalar apparent resistivities and impedance phases obtained by the VLF-MT measurements were plotted against distances from the MTL in Fig. 5. We can see that the apparent resistivity and the phase have almost similar values through the measuring line, respectively. The average apparent resistivity and phase are $86 \Omega \mathrm{m}$ and $38^{\circ}$, respectively.

The apparent resistivities and the phases at $7.8 \mathrm{~Hz}$ obtained by the ELF-MT soundings are shown in Fig. 6 . Here, the rotation angle is taken as $\mathrm{N} 10^{\circ} \mathrm{W}$. The distributions of apparent resistivities and phases at other frequencies in the ELF band are similar to those at $7.8 \mathrm{~Hz}$. Several features in Fig. 6 are obvious. One feature is that both phases $\left(\phi_{x y}\right.$ and $\left.\phi_{y x}\right)$ are higher than $45^{\circ}$ in the section from the MTL to $8 \mathrm{~km}$ north of the MTL. Another feature is recognized on the north side of the MTL that both $\phi_{x y}$ and $\phi_{y x}$ gradually decrease with distance from the MTL, while apparent resistivities (especially $\rho_{y x}$ ) gradually increase. The final feature is that $\phi_{x y}$ is lower than $45^{\circ}$ and $\phi_{y x}$ also becomes low in the section from the MTL to $5 \mathrm{~km}$ south.

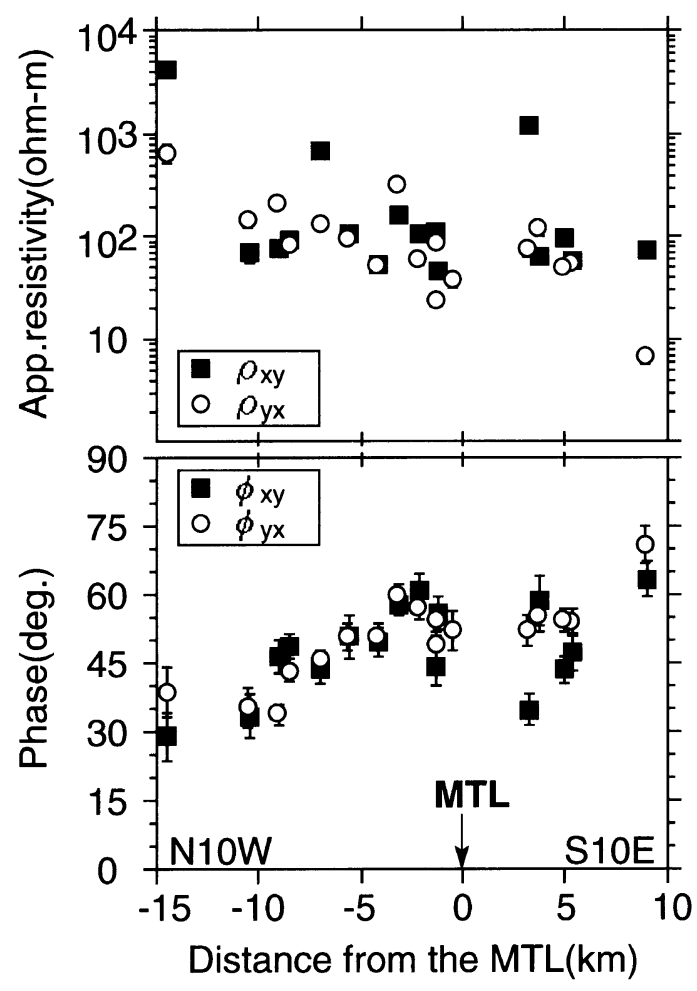

Fig. 6. Apparent resistivity and phase at $7.8 \mathrm{~Hz}$ along the profile with 95 percent standard error. Rectangles $\left(\rho_{x y}, \phi_{x y}\right)$ and circles $\left(\rho_{y x}, \phi_{y x}\right)$ are calculated from the electric field directed toward $\mathrm{N} 10^{\circ} \mathrm{W}$ and $\mathrm{N} 80^{\circ} \mathrm{E}$, respectively. 

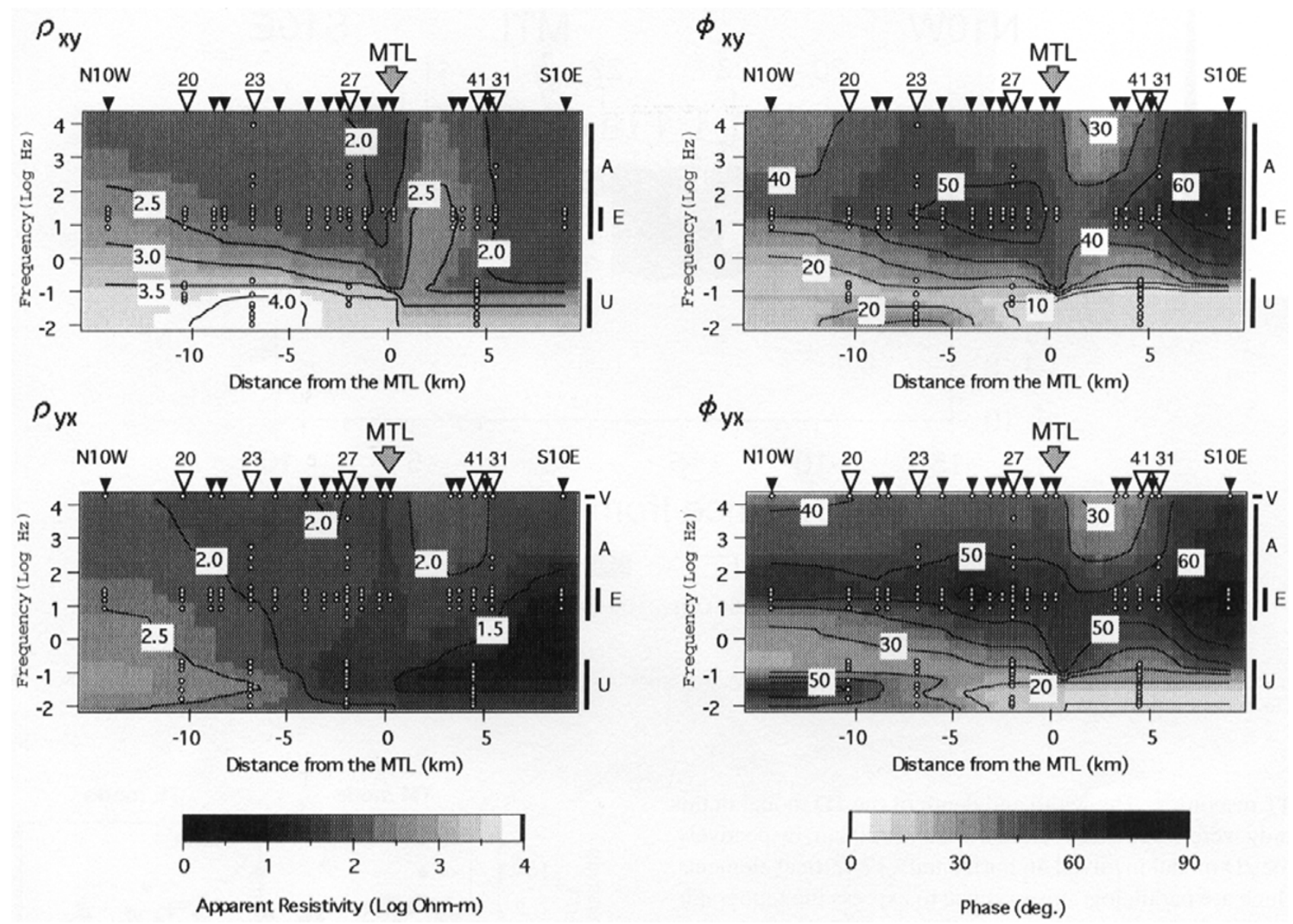

Fig. 7. Pseudosections of the apparent resistivity $\left(\rho_{x y}, \rho_{y x}\right)$ and the phase $\left(\phi_{x y}, \phi_{y x}\right)$ obtained by four kinds MT soundings. The frequency ranges for four MT soundings are shown by bold bars with the initials of VLF, ELF, ULF-MT and AMT. Gray arrows indicate the surface location of the MTL. Open and solid triangles indicate the locations of ULF-MT sites and the other sites, respectively. Open circles are the observed data points. Apparent resistivities and frequencies are expressed as logarithmic values.

The pseudosections of apparent resistivity and phase at the frequencies ranging from $17.4 \mathrm{kHz}$ to $0.01 \mathrm{~Hz}$ are shown in Fig. 7. The rotation angle is taken as $\mathrm{N} 10^{\circ} \mathrm{W}$ again. The pseudosections are drawn as smoothed contours on the basis of observed MT responses at sites 20,23, 27, 41 and 31 as shown in Fig. 10. The apparent resistivity and the phases obtained by the VLF and ELF-MT at all available sites are also added in Fig. 7. Note that $\rho_{y x}$ and $\phi_{y x}$ at $17.4 \mathrm{kHz}$ are estimated from the scalar impedance obtained by the VLFMT measurements using the N-S polarized magnetic field. Figures 7 and 10 are based on the results obtained by 3 or 4 kinds of MT measurements, which took place at the different electrode locations. In this case, the static shift (e.g., Jones, 1992) may affect the compilation of the apparent resistivity and lead to a fake curve. Although this problem is not severe if there is an overlapping frequency between the MT soundings, frequencies of our MT systems had no overlapping each other unfortunately. However, the electrode locations were set very closely each other, whose difference is within $20 \mathrm{~m}$. In addition, we carried out several VLF-MT measurements around each observed site and checked that there are no local resistivity anomalies near the electrodes. In fact, the apparent resistivities obtained by AMT and ELF-MT soundings show similar values at the neighbouring frequencies (4-30 $\mathrm{Hz}$ ). The average shift between AMT and ELF-MT apparent resistivity is 0.17 in a logarithmic scale. (See the apparent resistivity curves at Sites 23, 27 and 31 in Fig. 10 also.) We conclude that the effect of the static shift to the compilation is small enough to discuss the resistivity structure.

Three features are obvious in Fig. 7: low apparent resistivity at $0.1 \mathrm{~Hz}$, high apparent resistivity at $0.01 \mathrm{~Hz}$ and splitting of apparent resistivity curves. First, $\rho_{y x}$ around $0.1 \mathrm{~Hz}$ is low (about $10 \Omega \mathrm{m}$ ) at the south of the MTL and become higher as the site goes northward. Secondly, both $\rho_{x y}$ and $\rho_{y x}$ become large as the frequency decreases in the range lower than 0.1 $\mathrm{Hz}$ at all sites. Finally, the splitting of $\rho_{x y}$ and $\rho_{y x}$ curves is remarkable at frequencies lower than $1 \mathrm{~Hz}$ at sites 23, 27 and 41. The last feature is clearly shown in Fig. 10 rather than Fig. 7.

\section{Model Analyses and Their Results}

We estimated a two-dimensional (2D) resistivity model around the MTL to explain the observed apparent resistivities and phases at the frequencies from $17.4 \mathrm{kHz}$ to $0.01 \mathrm{~Hz}$. The finite element method described by Rodi (1976), modified by Ogawa (1988), was used for the calculation of the 2D 


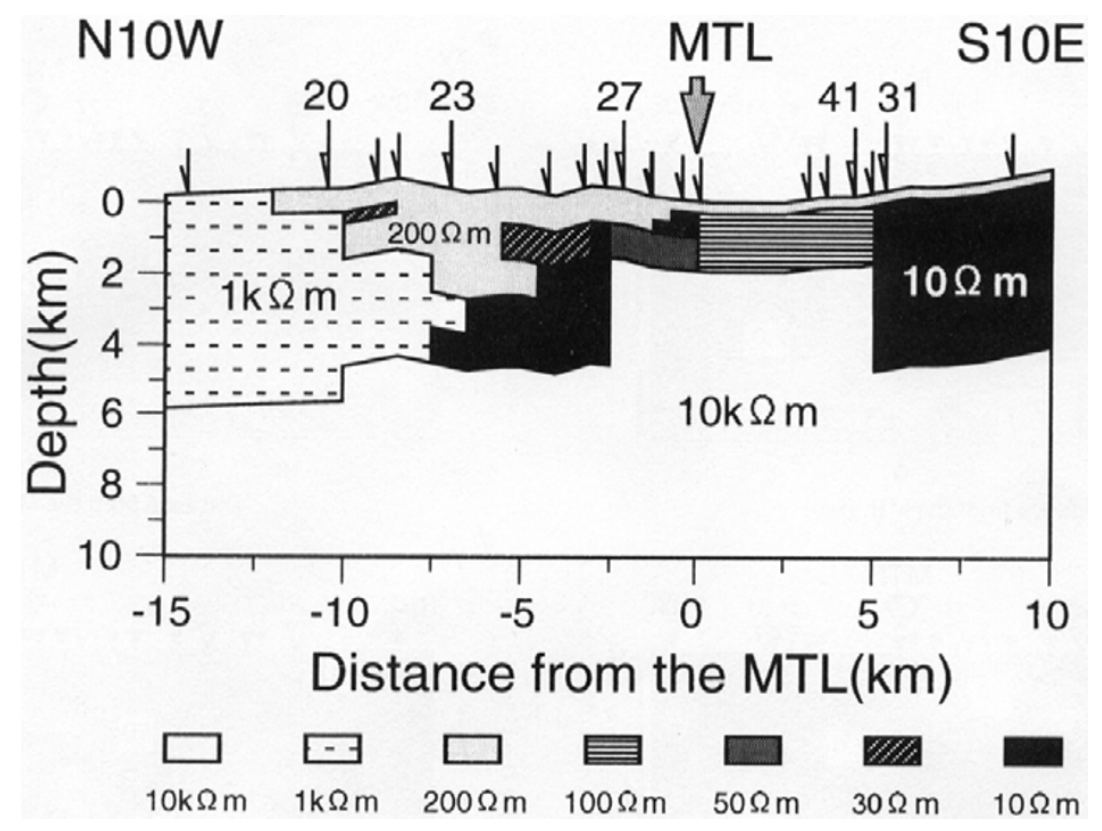

Fig. 8. Final two-dimensional resistivity model across the MTL. A gray arrow indicates the surface location of the MTL and smaller arrows indicate the location of sites.

MT responses. The width and depth of the $2 \mathrm{D}$ model in this study were assumed to be $1800 \mathrm{~km}$ and $900 \mathrm{~km}$, respectively. The 2D model involved 46 horizontal $\times 17$ vertical elements, which are parallelograms in shape to express the topographical relief. Smaller elements were arranged near the surface and the boundaries of resistivity. We took the Pacific Ocean and the Seto Inland Sea (Fig. 1) into consideration in the $2 \mathrm{D}$ model. The resistivity of sea water was specified to be $0.25 \Omega \mathrm{m}$. In $2 \mathrm{D}$ modeling, it is important to determine the strike of the $2 \mathrm{D}$ model. In this study, we adopted the strike of $2 \mathrm{D}$ models as $\mathrm{N} 80^{\circ} \mathrm{E}$. The transverse electric (TE) and the transverse magnetic (TM) modes are defined so that the electric field is along and perpendicular to $\mathrm{N} 80^{\circ} \mathrm{E}$.

The initial resistivities for the 2D model were given from the result of 1D forward modeling analyses (Kaufuman and Keller, 1981) at sites 23, 27 and 31. AMT responses are available at these sites and the static effects to the 1D modeling analysis can be reduced. TE mode responses were used for 1D modeling. On the basis of 1D models, we assumed the surface resistivity of the Izumi group and the Ryoke granite as $200 \Omega \mathrm{m}$ and $1 \mathrm{k} \Omega \mathrm{m}$, respectively. In the other regions, MT soundings on the Izumi group (Iseki et al., 1990; Shiozaki, 1994) and the Ryoke granite (Kashihara, 1992) show similar resistivities to the assumed values here and support our assumption. The surface resistivity of the Sambagawa metamorphic rocks is also assumed as $200 \Omega \mathrm{m}$ because the apparent resistivity at $17.4 \mathrm{kHz}$ in the southern area of the MTL is nearly as same as the northern one. Because the skin depth at $0.01 \mathrm{~Hz}$ may correspond to the depth of the mantle, which is highly conductive, we assumed resistivities at the depth from $100 \mathrm{~km}$ to $400 \mathrm{~km}$ as $50 \Omega \mathrm{m}$ and from $400 \mathrm{~km}$ to 900 $\mathrm{km}$ as $1 \Omega \mathrm{m}$ after Utada (1987). We changed the parameters of the 2D model about one hundred times by trial and error, and looked for the best-fit model.

The best-fit resistivity model is shown in Fig. 8. We cal-

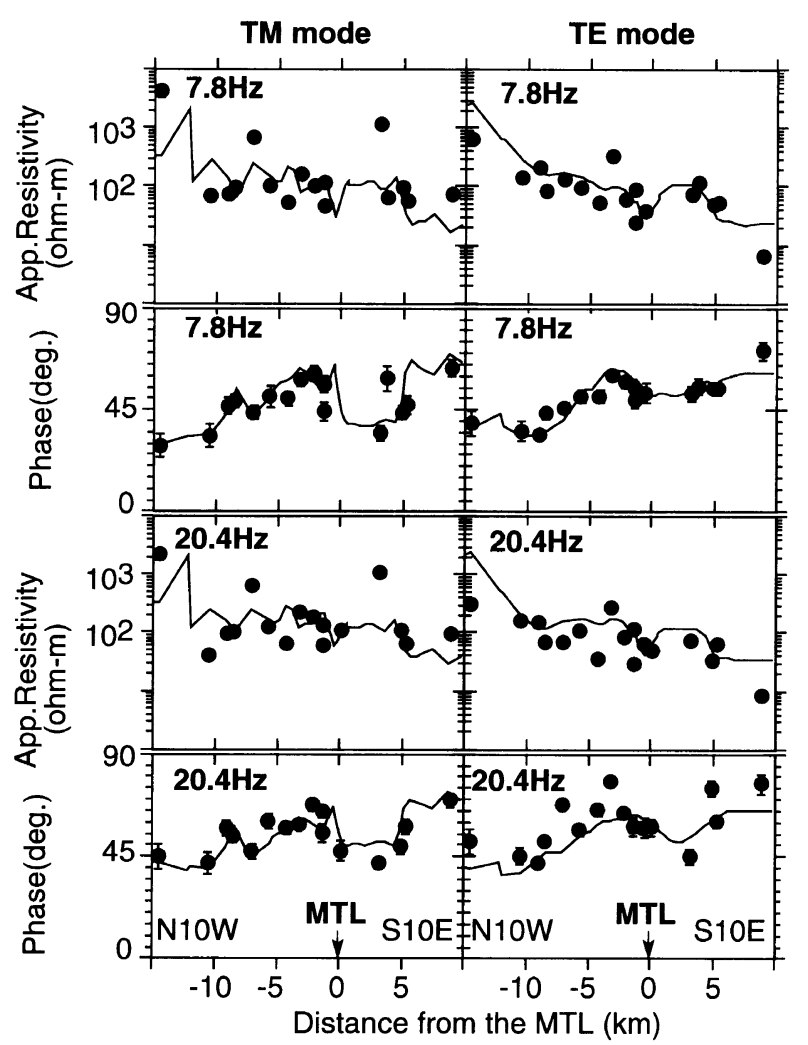

Fig. 9. Observed apparent resistivities and phases (circles) and calculated responses (lines) along the profile at $7.8 \mathrm{~Hz}$ and $20.4 \mathrm{~Hz}$. $\rho_{x y}$ and $\phi_{x y}$ are the TM mode responses, while $\rho_{y x}$ and $\phi_{y x}$ are of the TE mode.

culated the response functions from this model and have shown them together with observed values in Figs. 9 and 10. The most remarkable feature of the best-fit model is a northdipping resistivity boundary, which continues from the sur- 
$\begin{array}{ll}\text { - TM (cal) } & -- \text { TE (cal) } \\ \text { - TM (obs) } & \diamond \mathrm{TE}(\text { obs })\end{array}$
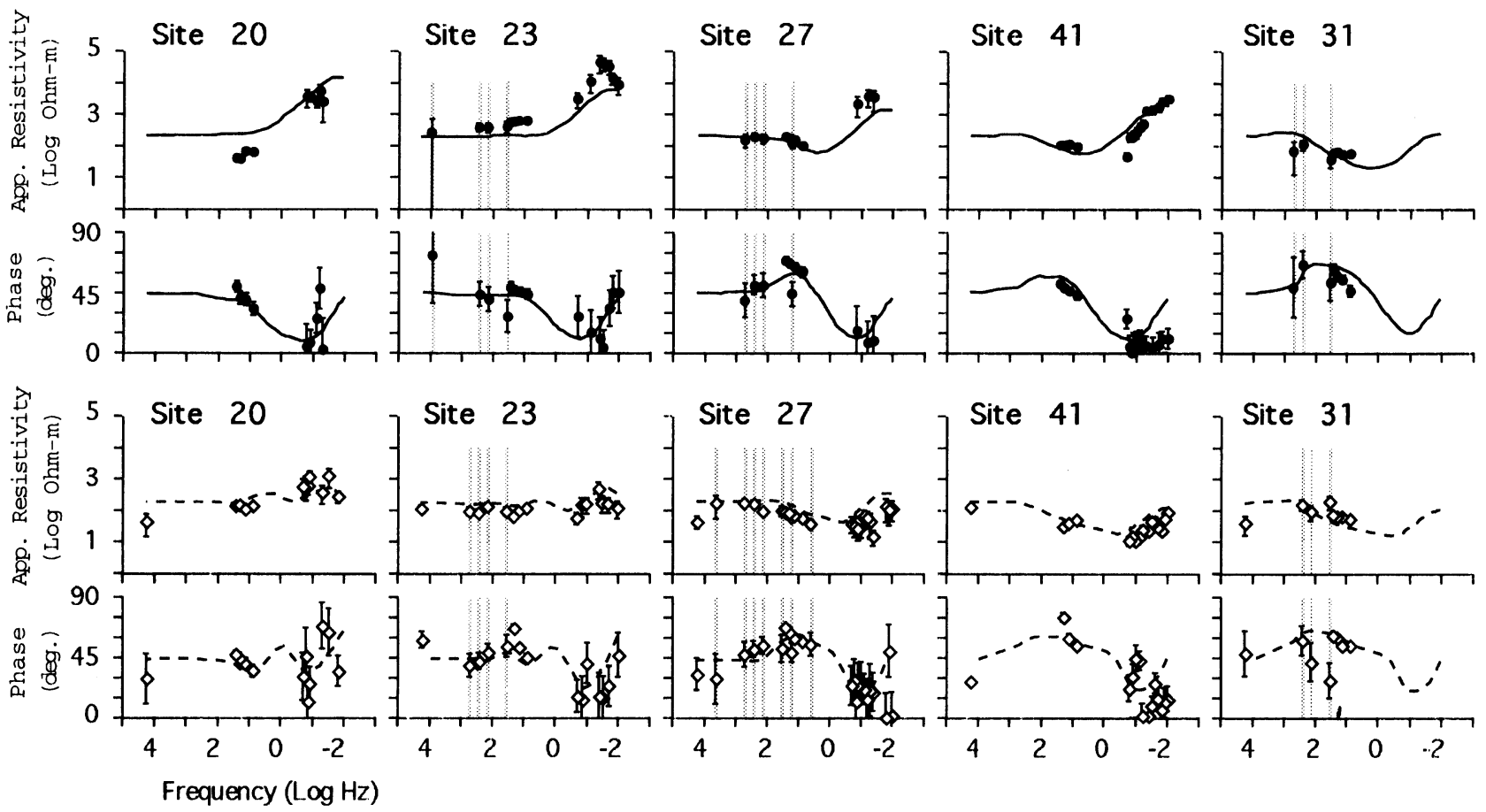

Fig. 10. Observed apparent resistivities and phases (TM, solid circles; TE, open lozenges) together with calculated responses (TM, solid lines; TE, dashed lines) in the frequency range from $10 \mathrm{kHz}$ to $0.01 \mathrm{~Hz}$. Gray bars indicate frequencies for the AMT sounding. Apparent resistivities and frequencies are expressed as logarithmic values.

face position of the MTL to the northern interior with dipping angle of about $30^{\circ}$. The boundary is mainly placed between the resistivity blocks of $200 \Omega \mathrm{m}$ and $10 \Omega \mathrm{m}$ and continues to the depth of about $5 \mathrm{~km}$. The north dipping can explain well the observed features such as the phases at 7.8-26.6 Hz decreasing as distance from the MTL increases, and $\rho_{y x}$ at $7.8-26.6 \mathrm{~Hz}$ increasing gradually on the north side of the MTL. Note that the observed profiles of $\rho_{x y}$ at $7.8 \mathrm{~Hz}-26.6$ Hz shown in Fig. 9, which are less smooth than $\rho_{y x}$, are also well explained by the best-fit model. Considering calculated responses from a model with a flat surface, we found that the observed feature of $\rho_{x y}$ is explained by the topographic effect on the TM mode.

In order to confirm the supposition that the resistivity boundary inclines northward, continuing from the surface position of the MTL to the interior, we calculated the responses from simplified 2D models with the various dipping angles of the boundary. Then, we compared them with the observed responses at the frequencies between $7.8 \mathrm{~Hz}$ and $26.6 \mathrm{~Hz}$. The 2D model is shown in Fig. 11(a) in which a flat surface with a dipping resistivity boundary is assumed. The calculated TM phases $\left(\phi_{x y}\right)$ at $7.8 \mathrm{~Hz}$ and $20.4 \mathrm{~Hz}$, which are most sensitive to the dipping angle, are shown in Fig. 11(c) and the root mean square (RMS) errors are also shown in Fig. 11(b). We found that the north-dipping resistivity boundary instead of being vertical is required to explaining the observed phases and apparent resistivities. Actually, $30^{\circ}$ is the most suitable dipping angle of this boundary for $7.8 \mathrm{~Hz}$ and $15^{\circ}$ for 20.4
$\mathrm{Hz}$ as shown in Fig. 11(c). Therefore, as shown in Fig. 8, two small resistivity blocks of $30 \Omega \mathrm{m}$ are necessary within the $200 \Omega \mathrm{m}$ block to fit calculated phases at $7.8 \mathrm{~Hz}$ and 20.4 $\mathrm{Hz}$ to observed ones simultaneously.

We also changed the dipping angle of the boundary below $5 \mathrm{~km}$ depth using the best-fit model and compared the calculated responses from the model with the observed responses. These 2D models, however, did not show significant decrease in RMS errors, because our site and the observed frequency range probably are not sensitive to such changes of the dipping angle. We concluded that the north-dipping resistivity boundary is confirmed up to a depth of several kilometers.

Conductive blocks $(10 \Omega \mathrm{m})$ exist beneath both the northern and the southern area of the MTL (Fig. 8). The northern conductive block is smaller than the southern one. The conductive blocks are necessary to explain the observed low apparent resistivity $\left(\rho_{y x}\right)$ around $0.1 \mathrm{~Hz}$ at sites 27 and 41 , and large phases at $7.8-26.6 \mathrm{~Hz}$. The observed induction arrows support the existence of the conductive blocks, that is, the induction arrows are directed southward at the northern site of the MTL and became smaller at the southern site of the MTL. We examined the robustness of the $10 \Omega \mathrm{m}$ zone below the studied area by changing its bottom depth. The $2 \mathrm{D}$ model used in the following sensitivity test was based on the best-fit model (Fig. 8) and were shown in Fig. 12(a). The responses from these 2D models with various bottom depths of the conductive zone are calculated at the frequencies ranging from $17.4 \mathrm{kHz}$ to $0.01 \mathrm{~Hz}$. The RMS errors corresponding 

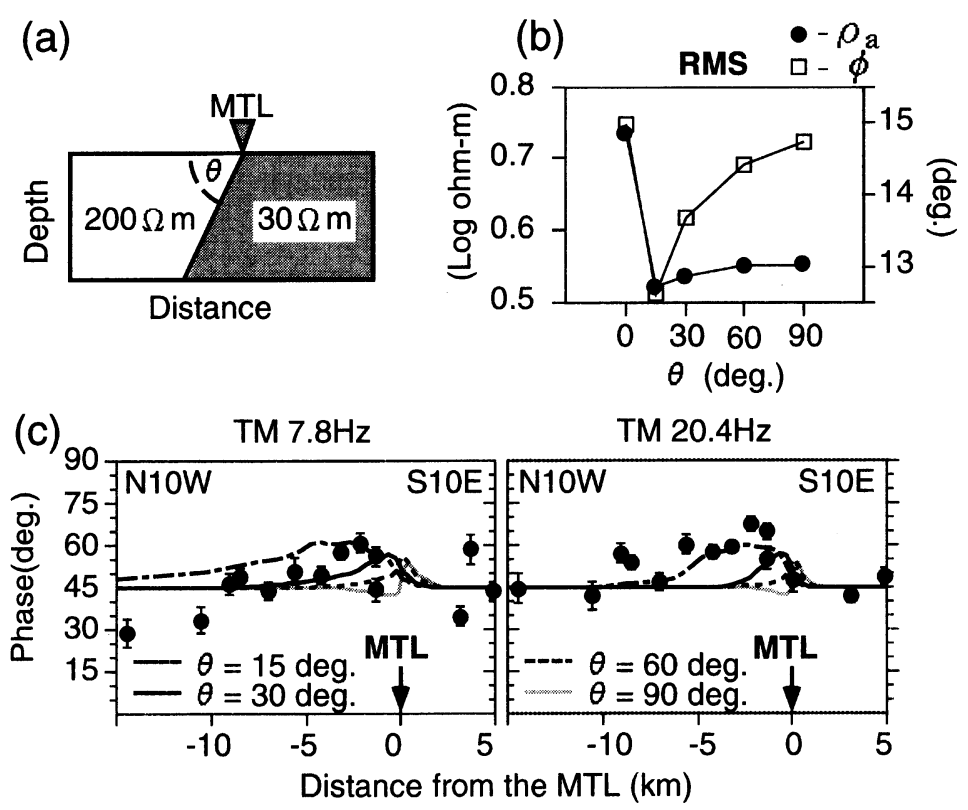

Fig. 11. (a) A simplified resistivity model for testing the sensitivity of the dipping resistivity boundary corresponding to the MTL on the surface. (b) RMS misfits of the apparent resistivity (circles) and the phase (rectangulars) as a function of dipping angles of the resistivity boundary. (c) Observed TM phases (circles) and calculated phases (lines) from the resistivity models with various dipping angles.

(a)

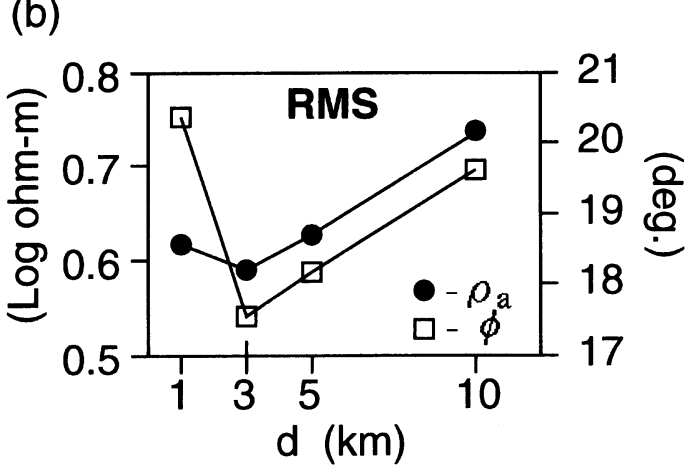

Fig. 12. (a) A resistivity model for testing the sensitivity of the thickness of the conductive zone beneath the southern area of the MTL. (b) RMS misfits of the apparent resistivity (circles) and the phase (rectangulars) as a function of depths of the bottom of the conductive zone.

to these 2D models shown in Fig. 12(b) let us conclude that the conductive zone extends up to about $3-5 \mathrm{~km}$ in depth.

The best-fit model, in addition, has other features. A resistivity block of $100 \Omega \mathrm{m}$ is appended to the shallow depth beneath the southern of the MTL. The $100 \Omega \mathrm{m}$ block is required to fit the low phase at $7.8 \mathrm{~Hz}-26.6 \mathrm{~Hz}$ observed in the section from the MTL to $5 \mathrm{~km}$ south. In the deeper part of the studied area, a resistive layer $(10 \mathrm{k} \Omega \mathrm{m})$ underlies in order to fit the increase in observed apparent resistivity at the frequencies lower than $0.1 \mathrm{~Hz}$. The resistive layer of 10 $\mathrm{k} \Omega \mathrm{m}$ is raised to the depth of about $2 \mathrm{~km}$ beneath the area between sites 27 and 41 . This rise is required to account for the splitting of apparent resistivity curves observed at sites 27 and 41.

\section{Discussion}

One of the most remarkable result in this study is that the north dipping resistivity boundary, corresponding to the MTL on the surface, explains our MT responses well. According to our model, this boundary can be traced to the depth of several kilometers and has the north dipping angle of $30^{\circ}$. Along the same measuring line, Ito et al. (1996) carried out seismic reflection and gravity surveys, of which the results helped us to interpret our resistivity structure. The profile is shown in Fig. 2 and their result is shown in Fig. 13 with our resistivity structure. They showed that north dipping reflectors can be traced almost continuously from the surface position of the MTL to about $5.5 \mathrm{~km}$ depth (from R1 to R1' in Fig. 13). They also constructed a density distribution model, which has a different density boundary continuing from the surface trace of the MTL to the interior. They concluded that the north dipping boundary of density agreeable with reflector R1 and $\mathrm{R}^{\prime}$ ' is preferable to a vertical boundary. It is noteworthy that the north dipping resistivity boundary in our model, which is derived from EM surveys only, is approximately coincident with the north dipping seismic reflector and the density boundary. On the basis of this coincidence, we conclude that the north dipping material boundary continues from the surface location of the MTL to about $5 \mathrm{~km}$ depth and this boundary possibly indicates the subsurface shape of 


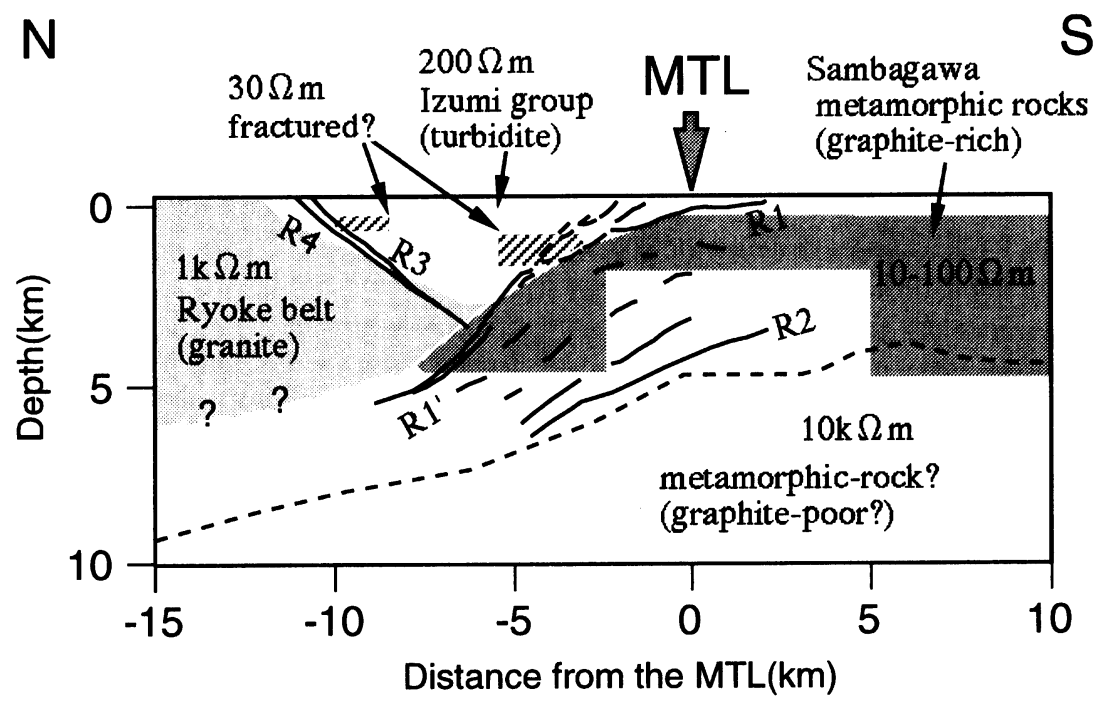

Fig. 13. Schematic drawing of the interpreted resistivity structure together with seismic reflectors (shown by solid lines; Ito et al., 1996). R1-R4 represent major reflectors (Ito et al., 1996). A dashed line indicates a distribution of top depths for a seismogenic zone beneath the surveyed area drawn after Kimura and Okano (1992).

the MTL. Because recent geophysical studies across the other sections of the MTL (e.g., Yusa et al., 1992) also show north dipping structure, the north dipping nature of the MTL is possibly found at the most part of the MTL.

Two low resistive $(30 \Omega \mathrm{m})$ blocks in the resistivity zone of $200 \Omega \mathrm{m}$ approximately coincide with the major seismic reflectors (Ito et al., 1996). Along active faults, low resistivity zones have been often found (e.g., Electromagnetic Research Group for the Active Fault, 1982, 1983; Ogawa et al., 1994). Causes of low resistivity along an active fault are interpreted either by a fracture zone (Handa and Sumitomo, 1985) or by organic carbon or graphite formed by the upwelling of deeply penetrating surface water in the fault zone (Jones et al., 1992). The $30 \Omega \mathrm{m}$ blocks are possibly interpreted as the low resistivity zones along the MTL and another active fault corresponding to the reflectors R3 and R4. Thus, we confirmed by the electromagnetic imaging of the MTL that the north-dipping resistivity boundary is not a mere material boundary such as an unconformity beneath the Izumi group but coincident with the MTL as the active fault.

A conductive zone (10-100 $\Omega \mathrm{m})$ underlying in the surveyed area does not coincide with major reflectors and is possibly related to the Sambagawa belt. A similar conductive zone was recognized in the Sambagawa belt along another survey line by Shiozaki (1994). In the Kii peninsular, east of our studied area, Fuji-ta et al. (1997) also detected a north-dipping conductor at the depth from the surface to about $8 \mathrm{~km}$, although the conductor is found at about $30 \mathrm{~km}$ south from the MTL and belongs to the different metamorphic belts from the Sambagawa belt. What produced such a conductive zone distributing in a metamorphic belt regionally? We suggest that this conductive zone is due to graphite in the metamorphic rocks. Recently, films of solid carbon on grain boundaries such as graphite have been proposed as one of the important conduction mechanisms in the crust and the upper mantle on the basis of the laboratory measure- ments (Duba and Shankland, 1982; Duba et al., 1988) and field observations (e.g., Stanley, 1989). In the surveyed area, most of the Sambagawa rocks belong to the Besshi nappe complex, which mainly consists of graphitic metapelite and greenstones of various types with minor amounts of chert and marbles (Takasu et al., 1994). Metapelite and greenstones, which are mostly metamorphosed from mudstone, usually include layered graphite along their schistosity (Hashimoto, 1987). Our interpretation is supported by the high resistivity value of the other Sambagawa metamorphic rock with lower content of graphite. In the Ikeda area, about $40 \mathrm{~km}$ west from the studied area, the Oboke nappe complex is distributed in the Sambagawa metamorphic belt (Fig. 1), composed of thick psammitic schist formation (Takasu et al., 1994). Psammitic schist, whose origin is mostly sandstone, maintains the original sand-grain texture (Hashimoto, 1987) and contains little layered graphite. Handa and Tamada (1981) and Shimoizumi and Kitamura (1988) applied the ELF-MT soundings in the Sambagawa belt around the Ikeda area and they showed high apparent resistivity values beyond $1 \mathrm{k} \Omega \mathrm{m}$ at the ELF band, which are quite larger than the values obtained on the Sambagawa belt in the surveyed area. The Oboke nappe complex underlies the surrounding area with a low dip-angle (Kenzan Research Group, 1984), and probably exists at a shallow depth beneath their studied area. We suppose that the difference of resistivity between two areas reflects the difference of the content of graphite in the Sambagawa metamorphic rocks, supporting our suggestion that graphite is a major cause of the conductive zone in our model. However other conduction mechanisms such as pore fluid (e.g., Laštovičková, 1991) also may be involved in our conductive zone.

A resistive layer of $10 \mathrm{k} \Omega \mathrm{m}$ exists in the south of the MTL, beneath depths of 2-5 km (See Fig. 8). There is no reasonable explanation for the existence of this layer. However, other geophysical studies show that the boundaries exist at a similar depth beneath the Sambagawa belt. Ito et al. (1996) 
observed a relevant weak seismic reflector at 4.5-6 km depth beneath the south of the MTL (R2 in Fig. 13). Kimura and Okano (1992) indicated that the top depth of the seismogenic zone beneath the Sambagawa belt is about $5 \mathrm{~km}$ deep in east Shikoku, which is also drawn in Fig. 13. In west and central Shikoku, Ohno et al. (1989) and Ohno (pers. comm.) described that a dense material distributes beneath the southern area of the MTL at the depth from the surface to about $2 \mathrm{~km}$. The reflectors, the gap of the seismicity and the density boundary roughly correspond to the top boundary of the electrically resistive layer. This correspondence suggests the existence of a sharp material boundary at 3-5 km depth beneath the Sambagawa belt. In our study, the high resistivity layer may consist of metamorphic rocks with little graphite such as the Oboke nappe complex. We can conclude, at least, that the zone at the depth from $5 \mathrm{~km}$ to $10 \mathrm{~km}$ beneath the surveyed area has less pore fluid or less conductive minerals such as graphite than the overlying layers.

The fault motion of the MTL in late Quaternary is interpreted as strike-slip on the basis of the geological studies (Okada, 1980). The present tectonic stress around the MTL is inferred from the seismic studies. Okano et al. (1980) studied the focal mechanism of microearthquakes in Shikoku, and concluded that most of focal mechanisms belong to a strikeslip type. Kimura and Okano (1992) estimated the distribution of maximum pressure axes from microearthquakes and most of pressure axes showed WNW-ESE direction, which are across the MTL obliquely. Thus, the present tectonic stress field in Shikoku is harmony with the recent strike-slip motion of the MTL. The faulting in 60-50 Ma was also strike-slip at the most part of the MTL (Ichikawa, 1980). However, such a strike-slip motion cannot form the gently north- dipping structure of the MTL found in our study. Although small and local dip displacements were found in 50 $2 \mathrm{Ma}$ (Ichikawa, 1980), they cannot form the north dipping structure possibly found at the most part of the MTL. On the other hand, our result rather supports the geological view that the north dipping MTL may have developed under a compressive stress perpendicular to the strike of the MTL in an early stage (late Cretaceous; 90-65 Ma). Ohtomo (1993), Yamamoto (1994) and other geologists described that the mylonite zone in the southern margin of the Ryoke belt was originally formed with a flat-lying configuration and they infer the formation of the initial MTL as a horizontal shear zone. We suggest that the north-dipping MTL was initially created by a horizontally compressive stress perpendicular to the MTL, and the recent strike-slip motion of the MTL is kept along the north-dipping MTL.

\section{Conclusion}

We obtained magnetotelluric data across the MTL and along the survey line of the seismic reflection study by Ito et al. (1996). The frequency range was from about $10 \mathrm{kHz}$ to $0.01 \mathrm{~Hz}$. We constructed the two-dimensional resistivity structure across the MTL using the observed responses. The final model required the north dipping resistivity boundary corresponding with the MTL on the surface, which separates the southern conductive zone from the northern resistive one. The north dipping resistivity boundary corresponds to the seismic reflector (Ito et al., 1996). The north dipping resistivity boundary implies the subsurface extension of the MTL and that the conductive zone consists of the Sambagawa metamorphic rock. The north dipping MTL is not due to the recent fault motion of the MTL, but it may have been caused by the large horizontal displacement perpendicular to the MTL, which occurred in the initial stage of the formation of the MTL.

Acknowledgments. We would like to thank Tanio Ito and Nobuhiro Isezaki in Chiba University for their helpful advice. We had useful discussions with many members of the Faculty of Science, Kobe University, especially Yo-ichiro Otofuji, Takao Miyata, Masayuki Hyodo, Kiyoshi Fuji-ta and Hirokazu Maekawa. We thank Yasuo Ogawa of the Geological Survey of Japan for providing the programs for the MT-forward analysis. Special acknowledgment goes to Tohru Mogi of Kyushu University and Masashi Shimoizumi of Kita-Kyushu Polytechnic College for their instrumental assistance in the AMT soundings. Koji Kashihara and Hiroyuki Hotani contributed to the field work. Comments from Shun Handa and an anonymous referee greatly improved the manuscript. This study was partly supported by the Japanese Ministry of Education, Science and Culture (grant-in-aid 03402017).

\section{References}

Bendat, J. S. and A. G. Piersol, Random Data: Analysis and Measurement Procedures, 407pp., Wiley-Interscience, New York, 1971.

Duba, A. G. and T. J. Shankland, Free carbon and electrical conductivity in the earth's mantle, Geophys. Res. Lett., 9, 1271-1274, 1982.

Duba, A. G., E. Huenges, G. Nover, and G. Will, Impedance of black shale from Munsterland 1 borehole: an anomalously good conductor?, Geophys. J., 94, 413-419, 1988.

Electromagnetic Research Group for the Active Fault, Low electrical resistivity along an active fault, the Yamasaki fault, J. Geomag. Geoelectr. 34, 103-127, 1982.

Electromagnetic Research Group for the Active Fault, Electrical resistivity structure of the Tanna and the Ukihashi faults, Bull. Earthq. Res. Inst., 58, 265-286, 1983 (in Japanese with English abstract).

Fuji-ta, K., Y. Ogawa, S. Yamaguchi, and K. Yaskawa, Magnetotelluric imaging of the SW Japan forearc - a lost paleoland revealed?, Phys. Earth Planet. Inter., 102, 231-238, 1997.

Groom, R. W. and R. C. Bailey, Decomposition of magnetotelluric impedance tensors in the presence of local three-dimensional galvanic distortions, J. Geophys. Res., 94, 1913-1925, 1989.

Handa, S. and N. Sumitomo, The geoelectric structure of the Yamasaki and the Hanaori faults, southwest Japan, J. Geomag. Geoelectr., 37, 93-106, 1985.

Handa, S. and O. Tamada, Observation of earth resistivity at Median Tectonic Line-Application of ELF-MT method to northeastern Shikoku district, Tsukumo Earth Sci., 16, 1-5, 1981 (in Japanese).

Hashimoto, M., Metamorphic Rocks in Japan, pp. 56-62, Iwanami Shoten Publishers, Japan, 1987 (in Japanese).

Ichikawa, K., Geohistory of the Median Tectonic Line of southwest Japan, Mem. Geol. Soc. Japan, 18, 187-212, 1980.

Iseki, S., H. Shima, S. Imamura, and J. H. Mims, Middle scale structure exploration by several kinds of electrical exploration-A study of the Median Tectonic Line in Wakayama Prefecture, Program Abstr. Fall. Meet. Soc. Explor. Geophys. Japan, 318-321,1990 (in Japanese).

Ito, T., T. Ikawa, S. Yamakita, and T. Maeda, Gently north-dipping Median Tectonic Line (MTL) revealed by recent seismic reflection studies, southwest Japan, Tectonophysics, 264, 51-63, 1996.

Jones, A. G., MT and reflection: an essential combination, Geophys. J. R. astr. Soc., 89, 7-18, 1987.

Jones, A. G., Electrical conductivity of the continental lower crust, in Continental Lower Crust, edited by D. M. Fountain, R. J. Arculus, and R. W. Kay, pp. 81-143, Elsevier, New York, 1992.

Jones, A. G., R. D. Kurtz, D. E. Boerner, J. A. Craven, G. W. McNeice, D. I. Gough, J. M. DeLaurier, and R. G. Ellis, Electromagnetic constraints on strike-slip fault geometry-The Fraser River fault system, Geology, 20, 561-564, 1992.

Kashihara, K., Analyses of the electrical resistivity structure around the MTL in northern Kii peninsula, Japan, by the magnetotelluric sounding method $^{\dagger}$, Master Thesis, Kobe Univ., 1992 (in Japanese) 
Kaufuman, A. A. and G. V. Keller, The Magnetotelluric Sounding Method, 955 pp., Elsevier, New York, 1981.

Kenzan Research Group, Stratigraphy and geologic structure of the Sambagawa metamorphic belt in the Oboke area, central Shikoku, Japan, Earth Sci. (Chikyu Kagaku), 38, 53-63, 1984 (in Japanese with English abstract).

Kimura, S. and K. Okano, A seismological examination of the Median Tectonic Line and its surrounding area in Shikoku, Southwest Japan, Mem. Geol. Soc. Japan, 40, 187-195, 1992 (in Japanese with English abstract).

Kimura, T., I. Hayami, and S. Yoshida, Geology of Japan, 287 pp., University of Tokyo press, Tokyo, Japan, 1991.

Laštovičková, M., A review of laboratory measurements of the electrical conductivity of rocks and minerals, Phys. Earth Planet. Inter., 66, 1-11, 1991.

Ogawa, Y., FORTRAN program codes for two-dimensional magnetotelluric forward and inverse analyses, Open-file Report. Geol. Surv. Japan, 59, 96 pp., 1988.

Ogawa, Y., M. Uyeshima, Y. Honkura, H. Utada, and S. Koyama, Audiofrequency magnetotelluric imaging of an active strike-slip fault, J. Geomag. Geoelectr., 46, 403-408, 1994.

Ohno, I., K. Takaichi, Y. Endo, R. Goto, A. Takahashi, M. Ishii, S. Okada, Y. Saiki, E. Ohtani, and M. Kato, Gravity survey in northwestern Shikoku, Japan, and subsurface structure of the Median Tectonic Line, J. Phys. Earth, 37, 385-400, 1989.

Ohtomo, Y., Origin of the Median Tectonic Line, J. Sci. Hiroshima Univ., Ser. C, 9, 611-669, 1993.

Okada, A., Quaternary faulting along the Median Tectonic Line of southwest Japan, Mem. Geol. Soc. Japan, 18, 79-108, 1980.

Okano, K., S. Kimura, T. Konomi, and M. Nakamura, Focal mechanism in Shikoku, Japan inferred from microearthquake observations, Mem. Fac. Sci. Kochi Univ., 1, Ser. B, 1-13, 1980.

Rodi, W. L., A technique for improving the accuracy of finite element solutions for magnetotelluric data, Geophys. J. R. astr. Soc., 44, 483-506, 1976.

Schmucker, U., Anomalies of geomagnetic variations in the southern United States, Bull. Scripps Inst. Oceanogr., 13, 165 pp., Univ. Calif. Press,
Berkeley and Los Angeles, 1970.

Shimoizumi, M. and T. Kitamura, Electromagnetic structure around the Median Tectonic Line in central Shikoku ${ }^{\dagger}$, Proc. Conductivity Anomaly Symp., 128-133, 1988 (in Japanese).

Shiozaki, I., The study of the electrical resistivity structures beneath the Chugoku and Shikoku district $^{\dagger}$, Ph.D. Thesis, Kobe Univ., 204 pp., 1994 (in Japanese).

Stanley, W. D., Comparison of geoelectrical/tectonic models for suture zones in the western U.S.A. and eastern Europe: are black shales a possible source of high conductivities?, Phys. Earth Planet. Inter., 53, 228-238, 1989.

Swift, C. M., A magnetotelluric investigation of an electrical conductivity anomaly in the southwestern United States, Ph.D. Thesis, M.I.T., 211 pp., 1967.

Takasu, A., S. R. Wallis, S. Banno, and R. D. Dallmeyer, Evolution of the Sambagawa metamorphic belt, Japan, Lithos, 33, 119-133, 1994.

Utada, H., A direct inversion method for two-dimensional modeling in the geomagnetic induction problem, Ph.D. Thesis, Univ. of Tokyo, 409 pp., 1987.

Vozoff, K., The magnetotelluric method in the Exploration of sedimentary basins, Geophysics, 37, 98-141, 1972.

Yamamoto, H., Kinematics of mylonitic rocks along the Median Tectonic Line, Akaishi Range, central Japan, J. Struct. Geol., 16, 61-70, 1994.

Yoshikawa, S., Y. Iwasaki, T. Ikawa, and H. Yokota, Geological structure of the MTL in west Wakayama by reflection seismic study, Mem. Geol. Soc. Japan, 40, 177-186, 1992 (in Japanese with English abstract).

Yusa, Y., K. Takemura, K. Kitaoka, K. Kamiyama, S. Horie, I. Nakagawa, Y. Kobayashi, A. Kubotera, Y. Sudo, T. Ikawa, and M. Asada, Subsurface structure of Beppu Bay (Kyushu, Japan) by seismic reflection and gravity survey, Zisin 2nd ser., 45, 199-212, 1992 (in Japanese with English abstract).

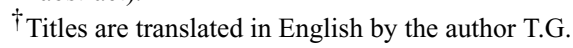

T. Goto (e-mail: tgoto@auecc.aichi-edu.ac.jp), S. Yamaguchi, N. Sumitomo, and $\mathrm{K}$. Yaskawa 